\title{
Epidermal inclusion cyst of the maxillofacial region
}

\author{
Colonel Priya Jeyaraj* \\ Command Military Dental Centre (Northern Command), Jammu \& Kashmir, India
}

\begin{abstract}
A Seborrheic or Epidermal inclusion cyst is basically an epidermoid cyst resulting from the traumatic implantation of epidermal elements into the dermis with their subsequent cystic transformation. A case of an epidermal inclusion cyst of the chin region is described in a 72 year old male, whose features were rather unusual, in that it presented as a fixed, indurated, inflamed, and extremely painful swelling associated with two draining extraoral sinuses, mimicking a submental space infection. The cyst was particularly persistent and recurred within a month of its excision and had to be re-excised along with the overlying epithelium.
\end{abstract}

\section{Introduction}

The terminology and nomenclature of the epidermal inclusion cyst is numerous and varied, and includes epidermal cyst, epithelial cyst, keratin cyst, follicular infundibular cyst, seborrheic cyst, sebaceous cyst, milia and so on [1]. It is basically an epidermoid cyst resulting from the traumatic implantation of epidermal elements into the dermis with their subsequent cystic transformation [2]. It represents one of the most common cutaneous cysts. An epidermal inclusion cyst (EIC) can be described as a dermal cystic enclosure of keratinizing squamous epithelium that is filled with keratin debris [3]. The terms traumatic epidermoid cysts and EIC describe the same phenomenon, and both indicate a traumatic etiology [4].

Epidermal inclusion cysts usually present as a firm, slow-growing, smooth, freely movable, painless mass or lump underneath the skin at the subcutaneous-dermal level, with an intact skin surface with no apparent drainage point. They contain soft, cheesy-like skin secretions. They usually appear on the scalp, face, neck, chest, upper back, genitals, or behind the ears. They are also often observed in the fingers, palms, and soles [3]. They are usually indolent in nature, slow to progress and remain asymptomatic; however, they may become inflamed or secondarily infected, which is partly due to chemotaxis induced for polymorphs by horny layer in the cyst, resulting in an increase in size and tenderness. They are treated by simple pericapsular excision without the need to excise the overlying epithelium and recurrence is rare.

A case of an epidermal inclusion cyst of the chin region is described, whose features were rather unusual, in that it presented as a fixed, indurated, inflamed, and extremely painful swelling associated with two draining extraoral sinuses, mimicking a submental space infection. The cyst was particularly persistent and recurred within a month of its excision and had to be re-excised along with the overlying epithelium.

\section{Case report}

A 72-year-old male patient reported with the complaints of a painful swelling under the chin for the past one month, which had been slowly increasing in size with discharge of pus from it. On examination, there was a single, localized, ovoid swelling below and on the lateral aspect of the chin on the left side extending from the symphyseal to the submental region, measuring approximately $4 \mathrm{~cm} \mathrm{X} 3 \mathrm{~cm}$ in size (Figure 1A and 1B). The swelling had diffused, and indistinct borders and the surface showed the presence of two extraoral sinus openings, one above and one below the inferior border of the mandible, which discharged foul smelling, purulent material (Figure 1C). The swelling was firm, tender, fixed to the underlying and adjacent tissues and the overlying skin was stretched and nonpinchable. There was induration around both the extraoral sinuses. Two submandibular lymph nodes were palpable on the left, which were tender and freely movable. On Intraoral examination, the patient was completely edentulous, and the swelling extended intraorally from 41 to 34 regions, with obliteration of the mucolabial fold and vestibular sulcus. Intraoral periapical and occlusal radiographs as well as Extraoral posteroanterior and lateral radiographs of the mandible and Orthopantomogram revealed absence of any bony involvement or pathology, with intact labial, buccal and lingual cortices and a normal trabecular pattern of the cancellous bone and an undisturbed contour and morphology of the inferior border of the mandible.

Clinical impression was that of a submental space infection with discharging sinuses. The differential diagnosis included a secondarily infected submental dermoid cyst, infected epidermoid or sebaceous cyst, or submental lymph node enlargement secondary to a granulomatous disease such as Cat-scratch disease or lymphoma, tubeculous lymphadenitis (scrofula) or HIV-related lymphadenopathy.

After a routine haemogram, urine examination and examination for $\mathrm{HIV}$ and $\mathrm{Hb}_{\mathrm{s}} \mathrm{Ag}$, an intraoral incisional biopsy was carried out after aspiration of the contents of the swelling using a wide bore needle. The aspirate, which was cheesy, yellowish-white in colour with a semisolid, granular, paste-like consistency, was sent for protein estimation (Figure $1 \mathrm{D}$ and $1 \mathrm{E})$. The total protein content was determined from cellulose acetate electrophoresis and was found to be high, $14.3 \mathrm{mg} / \mathrm{g}$ wet weight. Histopathologic examination of a biopsy specimen showed the presence of a cyst lining composed of keratinizing stratified squamous

Correspondence to: Colonel Priya Jeyaraj, Command Military Dental Centre (Northern Command), Jammu \& Kashmir, India, Tel: (91)9596840303; E-mail: jeyarajpriya@yahoo.com

Key words: seborrheic cyst; epidermal inclusion cyst; sebaceous cyst

Received: December 07, 2017; Accepted: December 27, 2017; Published: December 29, 2017 


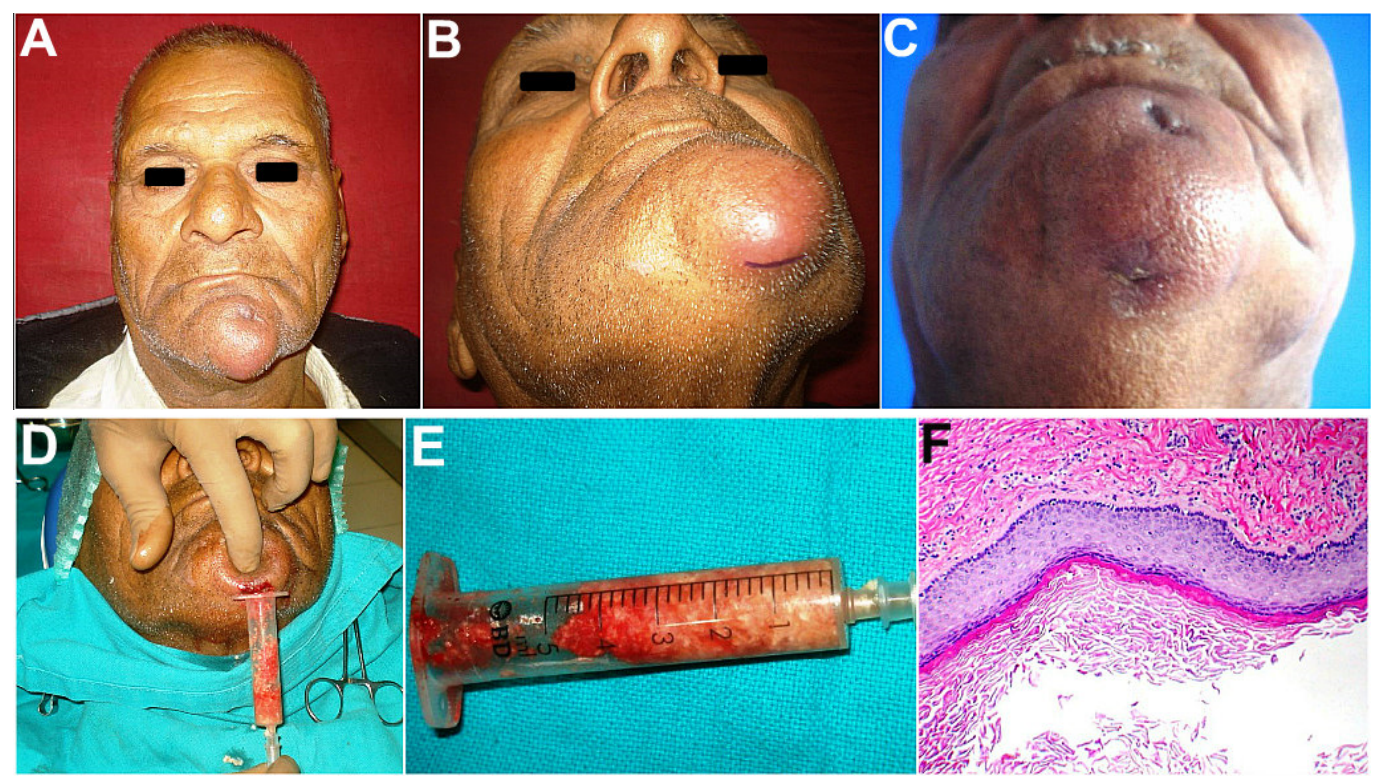

Figure 1. (A, B) 72 year old patient with an inflamed swelling in the mental region. (C) Two extraoral sinus openings draining foul smelling, purulent material. (D, E) Cheesy-white granular aspirate with a protein content of $14.3 \mathrm{mg} / \mathrm{gm}$ wet weight. (F) H \& E Section $40 \mathrm{X}$, showing a cystic lining composed of keratinizing stratified squamous epithelium, desquamated keratin within the lumen and a fibrous connective tissue wall with an inflammatory cell infiltration.

epithelium, desquamated keratin contents filling the lumen and a fibrous connective tissue wall containing no skin appendages, which confirmed the diagnosis of an epidermoid or epidermal inclusion cyst (Figure 1F). There also was a rich infiltration of polymorphonuclear leukocytes and lymphocytes, suggestive of secondary infection and inflammation.

The patient was taken up for complete excision of the cyst, together with sinus tract excision via combined transoral-trancutaneous approaches (Figure 2A and 2B). An intraoral incision was placed from incisor to bicuspid region on the left and submucosal dissection was carried out exposing the cyst. Cheesy, keratinous material extruded through the not so well-defined cyst wall, which showed extensive fibrosis with the surrounding tissues and had to be separated by meticulous sharp dissection. Excision proceeded down up to the buccal cortex of the symphyseal region, where a bony window was made to rule out intrabony extension or origin of the lesion. After excision of the entire cyst (Figure 2C), the sinus tracts were carefully dissected free from the surrounding tissues and their openings excised with a margin of surrounding skin. Skin closure was followed by a watertight intraoral closure of the wound. Post-operative healing proceeded uneventfully, and histopathologic examination of the excised specimen corroborated with the diagnosis of an epidermal inclusion or Seborrheic cyst. Healing proceeded satisfactorily (Figure 2D).

However, after a period of two months, the patient reported with recurrence of the lesion, presenting with a localized swelling, measuring $3 \times 2 \mathrm{~cm}$, in the left parasymphyseal region, which was extremely painful and tender (Figure 3A). The overlying skin was stretched, shiny and inflamed. The swelling was indurated with fixity to the surrounding tissues. There was no sinus opening. Intraorally, the swelling obliterated the labial vestibule in the region and reached up to the level of the edentulous alveolar crest. The yellowish intracystic contents were also visible through the stretched, translucent labial mucosa which had been distended by the cyst. Radiographs again revealed no bony pathology or involvement.

Owing to the recurrent nature, large size, obvious dermal involvement, together with repeated secondary infection and adherence of the dermoid cyst with the adjacent tissues, a wide local excision of the lesion was planned, using a combined transoraltrancutaneous route, with excision of the overlying skin, followed by reconstruction of the skin defect using an advancement flap (Figure $3 \mathrm{~B}$ and $3 \mathrm{C}$ ). 1:100,000 Adrenaline was infiltrated into the area and incision was made through the skin and subcutaneous tissue encircling the entire lesion, leaving a margin of $5 \mathrm{~mm}$ of normal appearing skin all around. The lesion in continuity with the overlying skin was carefully retracted upwards, taking care not to allow any of the cheesy keratinous material from within to extrude out into the surgical site. As there was extensive fibrosis and adherence of the lesion with the surrounding tissues, meticulous sharp dissection was employed to excise it completely. Electrocautery was used to control the bleeding points. It was also noticed that the Mental neurovascular bundle after exiting from the Mental foramen, traversed the lesion (Figure 3D) and hence it was excised in continuity with the lesion (Figure $3 \mathrm{E}$ and $3 \mathrm{~F}$ ) and the bleeding from the foramen controlled with elctrocautery. The incisive foramen and canal were located too and deroofed followed by thorough curettage to ensure no pathological remnant to eliminate all possible chances of a second recurrence (Figure 3E). The cyst was then excised in toto with the overlying skin along with its dermal appendages like hair follicles, sebaceous and sweat glands, to eliminate all possible sources of origin of the lesion. A modified transposition skin flap was raised and used to reconstruct the skin defect, followed by intraoral wound closure (Figure $3 \mathrm{G}$ and $3 \mathrm{H}$ ). Healing proceeded uneventfully thereafter (Figure 3I).

Histopathologic examination (Figure 4) demonstrated the typical features of the epidermal inclusion cyst, including shredded keratin fibers desquamating from the keratinized stratified squamous epithelial lining of the cyst (Figure 4A and 4B). In addition to the flaky keratin squames shed from the cornified epithelial lining there was seen an intense inflammatory infiltrate in the connective tissue wall (Figure 4C and $4 \mathrm{D}$ ), signifying chemotactic response to the keratin, as well as a secondary infection of the cyst. The luminal content of cyst contained lamillated horny keratin pearls which were shed from the cornified epithelial lining (Figure $4 \mathrm{E}$ and $4 \mathrm{~F}$ ). Exfoliated keratin squames were seen arranged in laminated layers, resembling an onion (Figure $4 \mathrm{G}$ and $4 \mathrm{H}$ ). 

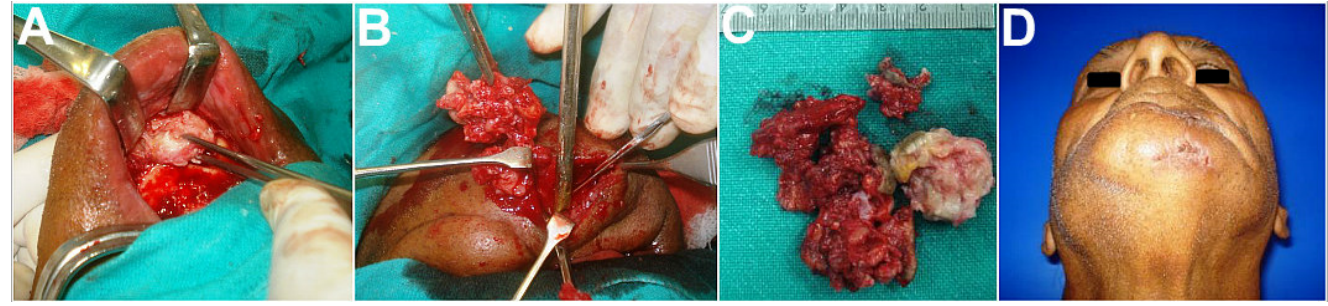

Figure 2. (A-C) A combined intra- and trans-oral approach to excise the lesion. (D) Healing at 2 weeks post op.
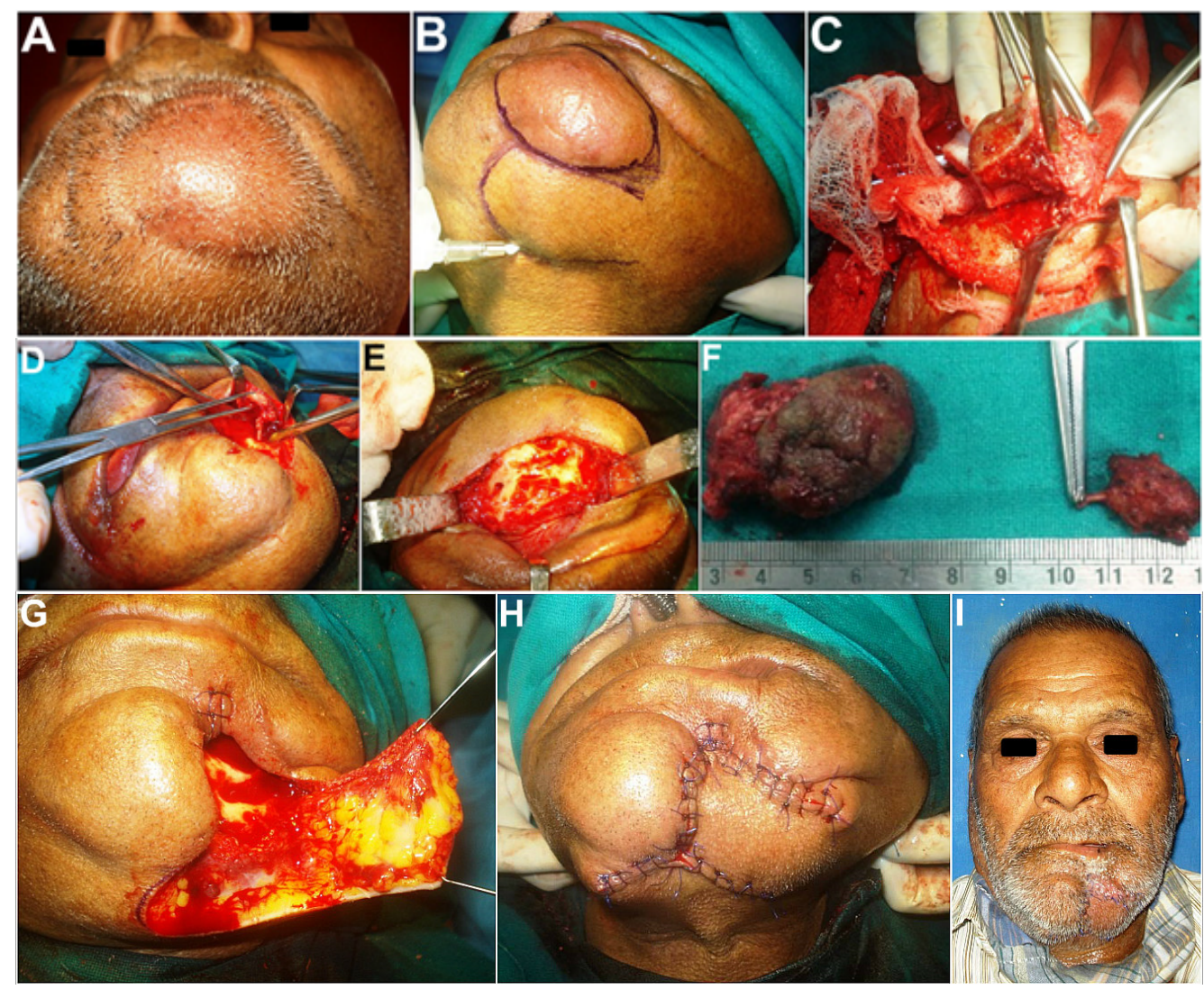

Figure 3. (A) Reccurrence of lesion two months thereafter. (B,C) Excision of the lesion along with the overlying skin. (D, E) Lesion found attached to the Mental nerve. Peripheral neurectomy of the Mental nerve and its Incisive branch carried out. (F) Excised specimen. On the right is the lesion excised in continuity with the Mental nerve. (G, H) Reconstruction of the skin defect using a modified transposition flap. (I) Healing at one week post op.

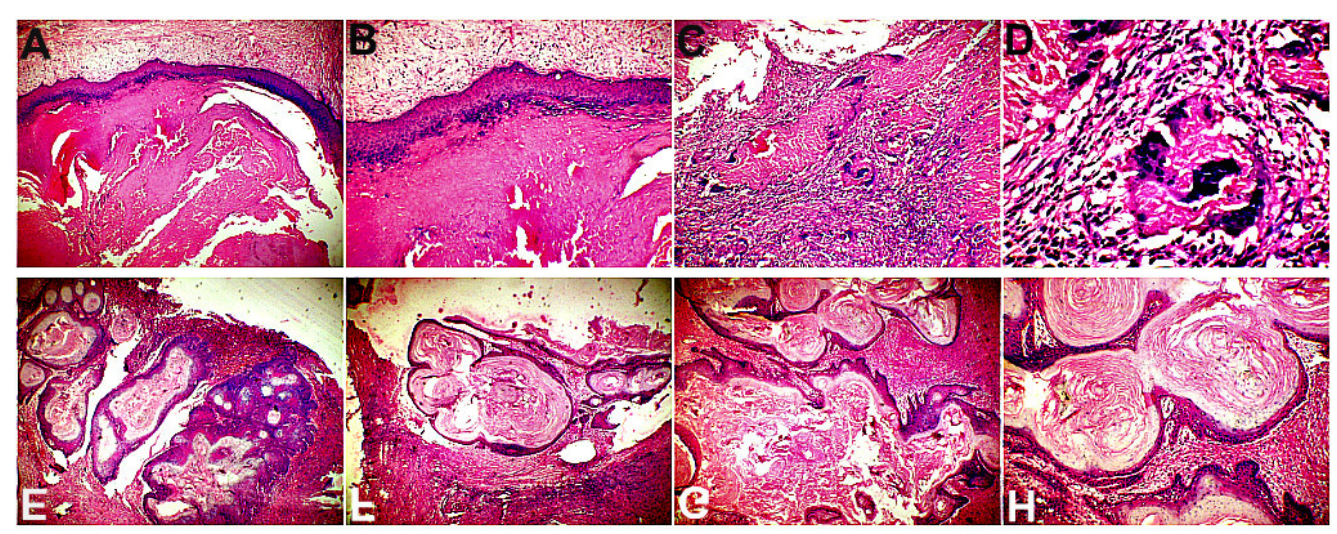

Figure 4. (A, B) H\&E Section $10 \mathrm{X}$ and $20 \mathrm{X}$, showing shredded keratin fibres desqumating from the keratinized stratified squamous epithelial lining of the epidermal inclusion cyst. Also seen are proliferating epithelial cells embedded within the fibrous connective tissue wall. (C, D) H\&E Section $20 \mathrm{X}$ and $40 \mathrm{X}$, showing an intense inflammatory cell infiltrate and a foreign body reaction with multinucleated giant cells within the connective tissue wall of the cyst. (E, F) H\&E Section 10X and 20X, demonstrating luminal content of lamillated horny keratin pearls which were shed from the cornified epithelial lining. (G,H) H\&E Section 20X and $40 \mathrm{X}$, showing exfoliated keratin squames, arranged in laminated layers, resembling an onion. 


\section{Discussion}

Historically, epidermal inclusion cysts have been referred to by various terms, including, sebaceous cysts, epidermal cysts, seborrheic cysts, follicular infundibular cysts and epidermoid cysts [1-3]. Epidermal inclusion cysts are approximately twice as common in men as in women. They may occur any time in life, but they are most common in the $3^{\text {rd }}$ and $4^{\text {th }}$ decades of life. The origin of the epidermal inclusion cyst is varied. They may form by sequestration and implantation of epidermal rests during embryonal period, occlusion of the pilosebaceous unit, or iatrogenic or surgical implantation of epithelium into the jaw mesenchyme [4-8] resulting in proliferation of epidermal cells within a circumscribed space of the dermis, in which case it is referred to as an epidermal inclusion cyst. Although most patients deny a history of trauma a mechanical pressure or a minor trauma may be a contributing factor. The source of this epidermis is often the infundibulum of the hair follicle, which may get implanted accidentally during shaving. Infundibular cyst refers to the site of origin of the cyst: the infundibular portion of the hair follicle. In fact, the majority of epidermal inclusion cysts originate from the infundibular portion of the hair follicle thus explaining the interchangeable [6-8], yet technically incorrect, use of these two terms.

Sebaceous cyst is a misnomer as these cysts are not of sebaceous origin. Human papillomavirus type 57 or 60 infections may be additional factors in the development of palmoplantar epidermoid cysts [9-11]. Oral and pharyngeal epidermoid cysts of the inclusion cyst variety also occur, but are rare in adults and are frequently so small that they are not biopsied. Syndromes associated with multiple cutaneous epidermoid cysts, such as Gardner syndrome, Gorlin syndrome and pachyonychia congenita [12], do not demonstrate cysts of the oral mucosa, but facial cysts may occur. Epidemiologic investigation has determined a prevalence rate of 1 cyst per 2,000 adults.

EICs lack ectodermal appendages, such as hair, nerve, bone, teeth, and sweat glands, which are associated with dermoid cysts. The cyst wall is composed of stratified epithelium and lumen that contain keratin in addition to desquamated cells, which are found in laminated layers [13]. Occasionally, the walls may be calcified. If the cyst ruptures, the result may be a granulomatous foreign body reaction, which can be diagnosed erroneously as an infection of the cyst. Inflammation is in part mediated by the horny keratinous material contained within, which has been shown to be strongly chemotactic for polymorphonuclear leukocytes, and partly due to secondary infection. Discharge of a foul smelling yellowish-white cheese-like material is a common complaint. They are most common in the third and fourth decades of life and are twice as common in men as in women.

Rarely, malignancies, including basal cell carcinoma, Bowen disease, SCC (most common of these rarities), mycosis fungoides, and melanoma in situ, have developed in epidermoid cysts. These cysts are benign lesions; however, very rare cases of various associated malignancies have been reported [14-18]. In the uncommon event of malignancy, rapid growth, friability and bleeding are characteristic features.

Dermoid and epidermoid cysts are a different entity from the epidermal inclusion cysts, are developmental in origin rather than traumatic and occur in the head and neck region with an incidence ranging from $1.6 \%$ to $6.9 \%$, and both cysts reported in less than $0.01 \%$ of all oral cavity cysts [19].

Epidermal inclusion cysts are of traumatic origin and are found mainly on palms and fingers of the hands and soles of the feet. They are believed to originate through implantation of epithelium by either surgical or accidental trauma into deeper mesenchymal tissue [20]. They are also often seen on the neck, chest and back [21].

Only about 7\% of all Epidermal inclusion cysts are found in the maxillofacial region, usually on the scalp (due to trauma while combing hair), on the hair bearing parts of face and neck (possibly due to traumatic implantation during shaving), periauricular and nasal areas [22]. The head and neck sites affected most frequently with these cutaneous cysts are the scalp (34\%), neck (18\%), periorbital area (17\%), cheeks (including lips;16\%), periauricular area (7.4\%), and nasal area (including forehead; 6\%) [23]. Only about $1.6 \%$ involves the oral cavity, mainly in the soft tissues of the tongue and floor of the mouth [24]. The size of these cysts normally varies from 1 to $5 \mathrm{~cm}$ in diameter. Only a few giant epidermal inclusion cysts have been reported in the literature and those of the face are even rarer [25].

A case of multiple huge epidermal inclusion cysts has been reported, which presented as longstanding multiple masses on the face and scalp region, which was misdiagnosed as neurofibromatosis owing to the accompanying history of seizure disorder and mental retardation. Mmagnetic resonance imaging helped to reach the correct diagnosis and total excision was carried out. Multiple huge epidermal inclusion cysts are sometimes mistaken as neurofibromatosis [26].

Epidermal inclusion cysts usually involve only the soft tissues, and intraosseous presentation is rare. There are very few reported intraosseous cases of epidermoid cysts, three having been reported in the jaw bones [24,27].

EICs have been found in the upper neck region as a result of ipsilateral radical mastoidectomy. Similarly, the following may lead to the formation of cysts in the temporal or infratemporal fossae regions - harvest of temporal fascia and facial nerve decompression. EICs may form after these procedures, possibly because the disease moves through the mastoid area into these adjoining regions by direct propagation. Tympanomastoid surgery, the insertion of ventilation tubes, and stapedectomy are examples of otological procedures that have been reported as etiologic factors in the development of EICs in areas such as the tympanic membrane, middle ear, and temporal fossae $[28,29]$. A recurrent intracranial epidermal inclusion cyst requiring combined treatment with neurosurgery has also been reported [30].

Treatment modalities include incision and drainage [30], which is fast and simple; however, recurrences are frequent if keratin producing lining of the cyst is not removed. Surgical excision is the treatment of choice as it is more definitive. The excision should be designed around the punctum and sutured immediately, or be allowed to drain prior to closure, especially if secondary infection is suspected. The possible complications of excising epidermal inclusion cysts are the risk of scarring and possible recurrence.

The characteristic histopathologic features demonstrated in this case included a cystic lining composed of keratinizing stratified squamous epithelium with a distinct granular cell layer (Figure 4). Shredded fibers and flakes of keratin and lamellated horny keratin pearls were found desquamated from the cornified epithelial lining and lying within the cyst lumen (Figure 4). The exfoliated keratin squames in many areas were found arranged in laminated layers, resembling an onion (Figure 4). Also seen, were proliferating epithelial cells embedded within the fibrous connective tissue wall of the cyst (Figure 4). The connective tissue wall also showed an intense inflammatory cell infiltrate and a foreign body reaction with multinucleated giant 
cells (Figure 4) probably as a chemotactic response to the keratin as well as secondary infection of the cyst. The etiology of the epidermal inclusion cyst of the chin in this case is likely to be trauma sustained while shaving. The case demonstrated a troublesome recurrence, after multiple attempts at surgical excision, most likely due to residual keratin producing cyst lining.

\section{Conclusion}

Epidermal inclusion cysts result from implantation and proliferation of epidermal elements in a space defined in the dermis, representing an unusual pathology in the submandibular region as described in this case. Although benign, a Seborrheic or Epidermal inclusion cyst can on rare occasions, be particularly persistent exhibiting a repeated recurrence after seemingly adequate and definitive management. In addition, secondary changes, such as inflammation and suppuration can further complicate management. The treatment of choice is comprehensive surgical excision, rather than incision and drainage. Care has to be taken to excise it in toto, often along with the overlying skin and the punctum involved, in order to prevent recurrences from the residual keratin producing lining of these cysts and to prevent possible malignant transformation.

\section{Disclosure of potential conflicts of interest}

The author of this article has not received any research grant, remuneration, or speaker honorarium from any company or committee whatsoever, and neither owns any stock in any company. The author declares that she does not have any conflict of interest.

\section{Research involving human participants and/or animals}

All procedures performed on the patients (human participants) involved were in accordance with the ethical standards of the institution and/or national research committee, as well as with the 1964 Helsinki declaration and its later amendments and comparable ethical standards.

\section{Ethical approval}

Although the use of intralesional injection of Polydocanol is a well-established and widely used treatment procedure for vascular malformations, the novel technique of its use as a single session sclerotherapy protocol, is described for the first time. Hence, this study was evaluated and approved by an Institutional ethical committee.

\section{Informed consent}

Informed consent was obtained from all the individual participants in this study.

\section{References}

1. James, William; Berger, Timothy; Elston, Dirk (2005) Andrews' Diseases of the Skin: Clinical Dermatology. (10 $10^{\text {th }}$ edn). Saunders.

2. Boffano P, Roccia F, Campisi P, Zavattero E, Gallesio C, et al. (2011) Epidermoid cyst of the temporal region. Oral Surg Oral Med Oral Pathol Oral Radiol Endod 112: e113-116. [Crossref]

3. Acarturk TO, Stofman GM (2001) Posttraumatic epidermal inclusion cyst of the deep infratemporal fossa. Ann Plast Surg 46: 68-71. [Crossref]

4. Sullivan DP, Liberatore LA, April MM, Sassoon J, Ward RF (2001) Epidermal inclusion cyst versus thyroglossal duct cyst: sistrunk or not? Ann Otol Rhinol Laryngol 110: 340-344. [Crossref]

5. Da Silva Rocha PCM, Costa-Neto H (2017) Unusual Epidermoid Cyst in the Hard Palate. Oral Sur Oral Med Oral Pathol Oral Radiol 124: e107.

6. Rodrigues R, Rodrigues FS (2014) Oral epidermoid cyst in buccal mucosa exhibiting an intense inflammatory gigantocellular reaction. Oral Sur Oral Med Oral Pathol Oral Radiol 117: 178-179.
7. Epstein WL, Kligman AM (1957) Epithelial cysts in buried human skin. AMA Arch Derm 76: 437-445. [Crossref]

8. Da Silva TP, Grotta R (2015) Epidermal Inclusion Cyst in Submandibular Region. Oral Sur Oral Med Oral Pathol Oral Radiol 120: 40-41.

9. Lee S, Lee W, Chung S, Kim D, Sohn M, et al. (2003) Detection of human papillomavirus 60 in epidermal cysts of nonpalmoplantar location. Am J Dermatopathol 25: 243-247. [Crossref]

10. Morgan MB, Stevens GL, Somach S, Tannenbaum M (2001) Carcinoma arising in epidermoid cyst: a case series and aetiological investigation of human papillomavirus. Br J Dermatol 145: 505-506. [Crossref]

11. Park HS, Kim WS, Lee JH, Yang JM, Lee ES, et al. (2005) Association of human papillomavirus infection with palmoplantar epidermal cysts in Korean patients. Acta Derm Venereol 85: 404-408. [Crossref]

12. Muzio LL, Mascitti M, Santarelli A (2017) Cystic lesions of the jaws: a retrospective clinicopathologic study of 2030 cases. Oral Sur Oral Med Oral Pathol Oral Radiol 124: $128-138$

13. Wade CL, Haley JC, Hood AF (2000) The utility of submitting epidermoid cysts for histologic examination. Int J Dermatol 39: 314-315. [Crossref]

14. Cameron DS, Hilsinger RL Jr (2003) Squamous cell carcinoma in an epiderma inclusion cyst: case report. Otolaryngol Head Neck Surg 129: 141-143. [Crossref]

15. Jayde BV, Upadya VH (2012) Epidermal inclusion cyst of the mandible after extraction of third molar: case report. Br J Oral Maxillofac Surg 50: 72-74. [Crossref]

16. Suliman MT (2005) Excision of epidermoid (sebaceous) cyst: description of the operative technique. Plast Reconstr Surg 116: 2042-2043. [Crossref]

17. Tanaka M, Terui T, Sasai S, Tagami H (2003) Basal cell carcinoma showing connections with epidermal cysts. J Eur Acad Dermatol Venereol 17: 581-582. [Crossref]

18. Swygert KE, Parrish CA, Cashman RE, Lin R, Cockerell CJ (2007) Melanoma in situ involving an epidermal inclusion (infundibular) cyst. Am J Dermatopathol 29: 564565. [Crossref]

19. Ozan F, Polat HB, Ay S, Goze F (2007) Epidermoid cyst of the buccal mucosa: a case report. J Contemp Dent Pract 8: 90-96. [Crossref]

20. Ramakrishna Y, Sudhindra B, Munshi AK (2009) Post-traumatic epidermoid inclusion cyst in the chin region. J Clin Pediatr Dent 33: 251-252. [Crossref]

21. King ES (1933) Post-traumatic epidermoid cysts of hands and fingers. Br J Surg 21: 29-43.

22. Handa U, Kumar S, Mohan H (2002) Aspiration cytology of epidermoid cyst of terminal phalanx. Diagn Cytopathol 26: 266-267. [Crossref]

23. Al-Khateeb, Al-Masri NM, Al-Zoubi F (2009) Cutaneous Cysts of the Head and Neck Taiseer Hussain American Association of Oral and Maxillofacial Surgeons. J Oral Maxillofac Surg 67:52-57.

24. Bhatt V, Evans M, Malins TJ (2008) Squamous Cell Carcinoma arising in the lining of an epidermoid cyst within the sublingual gland - a case report. Br J Oral Maxillofac Surg 46: 683-685. [Crossref]

25. Baek SO, Kim SW, Jung SN, Sohn WI, Kwon H (2011) Giant epidermal inclusion facial cyst. J Craniofac Surg 22: 1149-1151. [Crossref]

26. Hwang DY, Yim YM, Kwon H, Jung SN (2008) Multiple huge epidermal inclusion cysts mistaken as neurofibromatosis. J Craniofac Surg 19: 1683-1686. [Crossref]

27. Shivakumar MS, Yogesh TL (2015) Epidermal inclusion cyst of the buccal mucosa: A rare case report. Int J Med Dental Case Rep 1: 1-3.

28. Retnakumar K, Packiaraj I, Gen Morgan K, Alaguvel Rajan M, Abdul Rahman SM (2014) Unusual case of epidermoid cyst - A case report. Unique J Med Dent Sci 2: 80-281.

29. Ulku CH, Uyar Y, Kocaogullar Y, Avunduk MC, (2004) Iatrogenic epidermal inclusion cystof the parapharyngeal space: unusual complication of ear surgery. Cagatayhanulku, 1yavuz uyar, Yalcin kocaogullar,Mustafa cihatavunduk. Skull base: an interdisciplinary approach. Skull Base 14: 47-51. [Crossref]

30. Suliman MT (2005) Excision of epidermoid (sebaceous) cyst: description of the operative technique. Plast Reconstr Surg 116: 2042-2043. [Crossref]

Copyright: C2017 Jeyaraj CP. This is an open-access article distributed under the terms of the Creative Commons Attribution License, which permits unrestricted use, distribution, and reproduction in any medium, provided the original author and source are credited. 